\title{
Prevalence of HBsAg and Antibodies to Hepatitis C Virus among Female Sex Workers in Bangui
}

\author{
Serges Magloire Camengo Police ${ }^{1 *}$, Nathalie Philomène Boua-Akéléloํㅜ, Georges Service², \\ Eveline Mofini' ${ }^{1}$, Benoît Elowa1, Armelo Thibaut Yangba Kalebanga1, Bernard Bessanguem1, \\ Marcel Mbeko Simaléko ${ }^{3,4}$, Peggy Guérendo ${ }^{5}$, Henri Diemer ${ }^{4}$, Jospeh Roger Molowa Kobendo ${ }^{1}$ \\ ${ }^{1}$ Department of Hepato-Gastroenterology and Internal Medicine of “Amitié Sino-Centrafraine”, University Hospital Center, \\ Bangui, Central African Republic \\ ${ }^{2}$ Department of Internal Medicine "Maman Elisabeth Domitien”, University Hospital Center, Bimbo, Central African Republic \\ ${ }^{3}$ National Reference Center for Sexually Transmitted Infections and Antiretroviral Therapy, Bangui, Central African Republic \\ ${ }^{4}$ Department of Public Health, Faculty of Health Sciences, University of Bangui, Bangui, Central African Republic \\ ${ }^{5}$ Department Venerology Dermatology, National University Hospital Center, Bangui, Central African Republic \\ Email: ‘camengop@netcourrier.com,nathakel@yahoo.fr, servicegeorges@yahoo.fr,emofini@yahoo.com, \\ benoitelowa@gmail.com,yangbaarmelo@gmail.com,bernardbessan@gmail.com,mbeko@yahoo.fr, \\ pguerendo@yahoo.com,diemerhenri@yahoo.fr, josephrogermolowak@yahoo.fr
}

How to cite this paper: Police, S.M.C., Boua-Akélélo, N.P., Service, G., Mofini, E., Elowa, B., Kalebanga, A.T.Y., Bessanguem, B., Simaléko, M.M., Guérendo, P., Diemer, H. and Kobendo, J.R.M. (2020) Prevalence of HBsAg and Antibodies to Hepatitis C Virus among Female Sex Workers in Bangui. Open Journal of Gastroenterology, 10, 144-150. https://doi.org/10.4236/ojgas.2020.106015

Received: April 29, 2020

Accepted: June 9, 2020

Published: June 12, 2020

\section{Copyright $\odot 2020$ by author(s) and} Scientific Research Publishing Inc. This work is licensed under the Creative Commons Attribution International License (CC BY 4.0).

http://creativecommons.org/licenses/by/4.0/

\section{(c) (i) Open Access}

\begin{abstract}
Introduction: Hepatitis B virus (HBV) and Hepatitis C Virus (HCV) infection is a public health problem. Sex workers remain a vulnerable group. Objective: To determine the prevalence of $\mathrm{HBsAg}$ and hepatitis $\mathrm{C}$ virus (HCV) antibody transport among female sex workers (FSW) in Bangui. Patients and Methods: All FSW carriers of HBsAg and/or anti-HCV Antibodies were collected in a 6-month cross-sectional analytical study. The HBsAg research used the Monolisa $\mathrm{HBsAg}^{\oplus}$ (BioMérieux ${ }^{\circledR}$ ) technique, sandwich ELISA. HCV serology consisted of the search for anti HCV antibodies by monolisa HCV (BioMérieux ${ }^{\star}$ ), Elisa of the sandwich type. HIV serology used two Elisa tests (Genscreen ${ }^{\circledR}$ and Vironostika ${ }^{\circledR}$. Data analysis was done using Epi Info 3.5.1 software. The $\mathrm{Chi}^{2}$ test was used for comparison with a significance level $\mathrm{p}<0.05$. Results: Among the 345 FSW enrolled, 41 (11.9\%) were carriers of HBsAg and $3(0.8 \%)$ had anti HCV antibodies. The mean age was 21.3 years in HBsAg-positive FSW and 25 years in FSW with anti-HCV antibodies. FSW with HBsAg engaged in informal trade $(n=17)$, prostitution in bars or on the street $(n=15)$ and prostitution in the city $(n=9)$. On the other hand, the 3 FSW carrying anti-HCV antibodies were engaged in prostitution in the city. The 41 FSW HBsAg positive and 304 FSW HBsAg negative had at least 3 sexual partners. Anal pene-
\end{abstract}


tration during sexual intercourse was acknowledged by 20 FSW carrying HBsAg and 101 FSW HBsAg negative $(\mathrm{p}=0.0518)$. Among the 3 FSW $(0.8 \%)$ carrying anti-HCV antibodies, 2 were carrying HBsAg. HIV serology was positive in $66 \mathrm{FSW}(19.13 \%)$ including $15 \mathrm{FSW}$ coinfected with HIV/HBV $(\mathrm{p}=0.0025)$. Conclusion: The prevalence of hepatitis B is high among FSW. Awareness and prevention action must be taken in favor of this key population.

\section{Keywords}

HBsAg, Anti HCV Antibodies, Female Sex Workers, Bangui

\section{Introduction}

Female sex workers (FSW) are a population group not very well structured in the Central African Republic (CAR). They live in hiding. They are at risk of high vulnerability to Sexually Transmitted Infections (STIs) including Hepatitis B viral (HBV) and HIV [1]. In a country like CAR, where the prevalence of HBV infection is $10.6 \%$ [2] and that of HIV 4\% [3], FSW would be highly exposed to these two STIs. Chronic hepatitis B and C are a major public health problem worldwide. According to the World Health Organization (WHO), 325 million people worldwide are infected with HBV or HCV) [4]. Early detection and management of infected subjects would prevent the occurrence of complications, including cirrhosis and hepatocellular carcinoma. Our goal was to determine the prevalence and risk behaviors of hepatitis B and C transmission among FSW in Bangui.

\section{Patients and Methods}

We conducted a 6 month analytical cross-sectional study, from April 1 to August 31, 2012 at the National Reference Center for Sexually Transmitted Infections and Antiretroviral Therapy (NRCSTIART) in Bangui. During this study, we included, after informed consent, the Fsw in which the search for HbsAg, anti HCV antibodies and anti HIV antibodies was carried out. The search for HBsAg was carried out by the Monolisa HBsAg ${ }^{\oplus}$ (BioMérieux) technical, sandwich ELISA. HCV serology consisted of the search for anti HCV antibodies by Monolisa HCV $\left(\right.$ BioMérieux $\left.{ }^{\circledR}\right)$, Elisa of the sandwich type. HIV serology used two Elisa tests $\left(\right.$ Genscreen $^{\oplus}$ and Vironostika ${ }^{\oplus}$ ). Recruitment of FSW was made possible through an interview with two of the leaders to explain the merits of the study. During the interview, we informed them that their activities exposed them to STIs, some of which may be asymptomatic, notably hepatitis $B$, but also hepatitis $C$, which can later be revealed by complications. It is important that these infections can be found. We reassured them that clinical examination, biological examinations (HIV serology, HBV serology, HCV serology, treponemal serology, chlamydiae serology, vaginal sampling, cyto-bacteriological examination of urine) and treat- 
ment of STIs outside of chronic hepatitis B was free, covered by NRCSTIART. Round-trip transportation of the FSW for maintenance, sampling, reporting of results was the responsibility of NRCSTIART. The return transport costs were 1000 FCFA or $1.52 €$. The parameters studied were epidemiological (age, sex, risk factors), biological (HBV, HCV, HIV serology). FSW carrying HBsAg and/or anti-HCV antibodies were entrusted to the hepatologist for the evaluation of chronic hepatopathy. FSW infected with HIV and/or co-infected with HBV/HIV benefited from a free pre-therapeutic assessment, notably the hemogram, transaminases, prothrombin level, glycemia, creatininaemia, HIV viral load, T lymphocyte count CD4. They were put on antiretroviral treatment, the therapeutic protocol of which included Tenofovir and Emtricitabine. The FSW met the inclusion criteria but were not included in the study but refused to participate in the study. Our sample was of convenience taking into account all the FSW meeting our criteria. Data entry and analysis was done using Epi info 3.5.1 software. The chi2 test was used for comparison with a significance level $\mathrm{p}<0.05$.

\section{Results}

During the study period, we collected $345 \mathrm{FSW}$, of which 41 (11.9\%) were carriers of HBsAg, $3(0.8 \%)$ were carriers of anti-HCV antibodies and $66(19,13 \%)$ infected with HIV. Among the 41 FSW carrying HBsAg, 15 (36.6\%) had coinfection with HIV. Two of the 3 FSW (66.6\%) with anti-HCV antibodies had HIV coinfection. The average age of FSW with HBsAg was $21.3 \pm 6.6$ years, while those with anti-HCV antibodies had an average age of $25 \pm 3.2$ years. The level of education of HCV infected TS is shown in Figure 1.

All TSs who had Anti HCV Antibodies had a secondary level.

Table 1 shows the activities of the FSW and the reasons that led them into sex work.

The 3 FSW carrying anti HCV antibodies were involved in prostitution in bars or on the street. The death of one of the parents and the abandonment by the parents were the reasons for sex work in 1 and 2 cases, respectively, for those who carried anti-HCV antibodies.

History of FSW infected with HBV and risk factors are presented in Table 2.

The average daily amount of alcohol consumed by FSW carrying HBsAg is 60 $\mathrm{g}$ with extremes of 20 and $90 \mathrm{~g}$. The $3 \mathrm{FSW}$ carrying anti-HCV antibodies consumed alcohol, the respective daily amount of $40 \mathrm{~g}, 70 \mathrm{~g}$ and $120 \mathrm{~g}$. The number of FSW infected HBV sex partners ranged from 3 to 13. Drug use intravenously was not found in our FSW. During a day, FSW infected with HBV could have had on average 4 sexual relations with extremes ranging from 2 to 8 . All FSW carrying anti-HCV antibodies had at least 3 sexual partners with extremes ranging from 3 to 11. They could have an average of 5 sexual intercourse per day with extremes ranging from 4 to 6 . All FSW infected with HBV and carrying anti-HCV antibodies had fixed partners and occasional partners. 


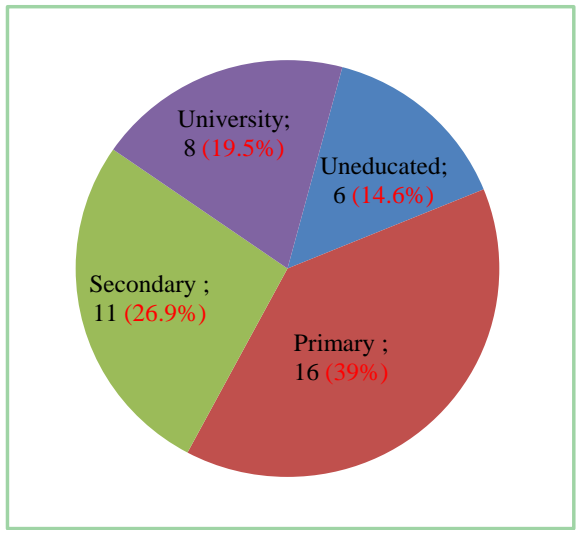

Figure 1. Level of education of FSW HBsAg positive.

Table 1. Level of education and reason for sex work of FSW HBsAg positive.

\begin{tabular}{cccc}
\hline & HBsAg positive & HBsAg negative & $\mathrm{p}$ \\
\hline Activity & 17 & 148 & 0.6848 \\
Informal trade & 15 & 97 & \\
Prostitution in bars or on the street & 9 & 59 & 0.6507 \\
Prostitution in the city & & & \\
Reasons & 11 & 99 & \\
Parents' deaths & 8 & 65 & \\
Abandonment by parents & 9 & 58 & \\
Support studies & 7 & 52 & \\
Train by girlfriends & 6 & & \\
Seek sexual pleasure & & & \\
\hline
\end{tabular}

Table 2. History of TS HBsAg positive and risk factors.

\begin{tabular}{cccc}
\hline & HBsAg positive & HBsAg negative & $\mathrm{p}$ \\
\hline Background & 10 & 23 & 0.0005 \\
Dental care & 5 & 3 & 0.0899 \\
Excision & 3 & 11 & 0.5344 \\
Tattoo & 2 & 6 & 0.7667 \\
Surgery & 41 & 261 & 0.0001 \\
Alcohol consumption & & & \\
Risk factors & 41 & 304 & \\
Sex partners $\geq 3$ & 20 & 101 & 0.0501 \\
Anal penetration & 15 & 51 & 0.0024 \\
HIV infection & 7 & 67 & 0.4674 \\
\hline Condom use & & &
\end{tabular}




\section{Discussion}

Our study has limitations, however. We could not do the HCV viral load to confirm or rule out chronic carriage. HCV viral load and non-invasive fibrosis tests were not feasible at the time in Bangui. Their very high cost did not allow accessibility to FSW. Also, HBV mono-infected FSW only benefited from clinical and ultrasound monitoring. They were unable to do the HBV viral load, as well as the non-invasive fibrosis tests. The search for co-infection with the hepatitis D virus was not also carried out in FSW infected with HBV. We only looked for HBsAg, the negativity of which does not formally exclude HBV infection. It could be that among FSW, HBsAg negative, some had occult chronic hepatitis B. It should be interesting to look for at least $\mathrm{HBsAg}$, anti $\mathrm{HBc}$ antibodies and anti $\mathrm{HBs}$ antibodies. Only FSW co-infected with HBV/HIV had received antiretroviral therapy. Despite these limitations, this first study in the Central African Republic revealed that FSW exist in Bangui and constitute a group vulnerable to STIs. The frequency of HBV infection in the FSW of our series of $11.9 \%$ is slightly higher than that observed in the general population in the Central African Republic [2] and much higher than that reported in Rwanda which is $2.5 \%$ [5], in Congo/Brazzaville, $4.2 \%$ [6], in Mexico, $0.2 \%$ [7], in Iran, 1.1\% [8], in Greece, $1.3 \%$ [9], in Venezuela, 3.8\% [10]. In contrast, in Nigeria [11] and Brazil [12], the authors reported a frequency of $17.1 \%$. The prevalence of HBV infection is higher in our study and in that conducted in Nigeria [11] and even in Rwanda [5] and Congo-Brazzaville [6]. It would be due to the fact that we are in the zone of high endemicity of hepatitis B and probably by the high level of risk taking of FTS. The prevalence of anti HCV antibodies in our study of $0.8 \%$ is almost similar to that observed in Congo-Brazzaville, Venezuela [10], and Brazil [12], Czech Republic [13], which is respectively $0 \%, 7 \%, 0.5 \%, 0.7 \%$ and $1 \%$. In contrast, in Rwanda, the authors reported a prevalence of HCV of $1.4 \%$ [5] and in Kinshasa, a prevalence of $6.6 \%$ [14]. The low prevalence of contact with HCV in our study and that of other authors is due to the fact that HCV is exceptionally transmitted through sexual intercourse. In Kinshasa, the authors reported that the high prevalence of anti-HCV antibodies was linked to a history of blood transfusion [14]. However, in a cohort in Vancouver among FSW, some of whom used the drug intravenously, the authors reported a prevalence of $42.8 \%$ [15]. In Greece, the authors reported a prevalence of anti-HCV antibodies of $2.3 \%$ among FSW, some of whom used intravenous drugs [9]. HBV/HIV coinfection was observed in 36.6\% of FSW infected with HBV in our series. It is likely that it was the HIV infection that would have favored the transition to chronicity of the HBV infection, if the latter had occurred after the HIV infection. FSW co-infected with HBV/HIV, if they were not detected and put on treatment, they could progress to the stage of complications, notably cirrhosis and/or hepatocellular carcinoma. The two FSW coinfected with HIV/anti-HCV antibodies underwent a clinical examination and an abdominal ultrasound every 6 months in order to look for complications. The average age of FSW infected with HBV in our study of 21.3 years \pm 6.6 is lower 
than that of FSW in Nigeria [11], Italy [16] and Albania [17] which was respectively 26, 7 years; 24 and 28 years old. The young age of FSW in our study may explain exposure to sexually transmitted infections (STIs). They are likely to be unable to impose STI prevention measures on their partners. Especially since the latter live in precariousness due to financial difficulties due to the death of the parents, abandonment by the parents, pushing them into sex work whose only objective is to make money in order to provide for the different needs. The average of FSW with anti-HCV antibodies in our study was $25 \pm 3.2$ years, less than $29.61 \pm 8.4$ years of FSW in Venezuela [10] and 34 years of FTS in Vancouver [15]. FSW infected with HBV and HCV are younger in our study. The death of the parents and the lack of family support would have forced the FSW of our series to engage in prostitution very early. It is important that the FSW be made aware of STIs and prevention measures. All of the FSW in our study had a minimum of three sexual partners. The more the number of sexual partners increases, the more the daily number of sexual intercourse increases, the more the risk of contracting STIs increases especially since very few FSW used the condom and that some had anal intercourse, which is traumatic. Anal penetration was also the risk factor found in FSW in Mexico [7].

\section{Conclusion}

The prevalence of chronic hepatitis B and HIV is high among FSW in Bangui. That of HCV is weak. Information and education campaigns must be carried out in favor of FSW to encourage early detection and vaccination against HBV. It is important to set up a national program to fight viral hepatitis.

\section{Conflicts of Interest}

The authors declare no conflicts of interest regarding the publication of this paper.

\section{References}

[1] Nagot, N., Ouangré, A., Cartoux, M., et al. (2002) Spectrum of Commercial Sex Activity in Burkina Faso: Classification Model and Risk of Exposure to HIV. Journal of Acquired Immune Deficiency Syndromes, 29, 517-521. https://doi.org/10.1097/00126334-200204150-00013

[2] Komas, N.P., Vickos, U., Hübschen, J.M., et al. (2013) Cross-Sectional Study of Hepatitis B Virus Infection in Rural Communities, Central African Republic. BMC Infectious Diseases, 13, Article No. 286. https://doi.org/10.1186/1471-2334-13-286 http://www.biomedcentral.com/1471-2334/13/286

[3] ONUSIDA (2019) https://www.unaids.org/fr/keywords/central-african-republic

[4] WHO Global Hepatitis Report 2017. https://www.who.int/fr/news-room/detail/21-04-2017-new-hepatitis-data-highlightneed-for-urgent-global-response

[5] Mutagoma, M., Nyirazinyoye, L., Sebuhoro, D., et al. (2017) Syphilis and HIV Prevalence and Associated Factors to Their Co-Infection, Hepatitis B and Hepatitis C 
Viruses Prevalence among Female Sex Workers in Rwanda. BMC Infectious Diseases, 17, Article No. 525. https://doi.org/10.1186/s12879-017-2625-0

[6] Niama, F.R., Loukabou Bongolo, N.C., Mayengue, P.I., et al. (2017) A Study on HIV, Syphilis, and Hepatitis B and C Virus Infections among Female Sex Workers in the Republic of Congo. Archives of Public Health, 75, 1-8.

https://doi.org/10.1186/s13690-017-0189-5

[7] Juárez-Figueroa, L., Uribe-Salas, F., Conde-Glez, C., et al. (1998) Low Prevalence of Hepatitis B Markers among Mexican Female Sex Workers. Sexually Transmitted Infections, 74, 448-450. https://doi.org/10.1136/sti.74.6.448

[8] Kassaian, N., Ataei, B., Yaran, M., et al. (2011). Hepatitis B and C among Women with Illegal Social Behavior in Isfahan, Iran: Seroprevalence and Associated Factors. Hepatitis Monthly, 11, 368-371.

[9] Papadogeorgaki, H., Caroni, C., Frangouli, E., et al. (2006) Prevalence of Sexually Transmitted Infections in Female Sex Workers in Athens-Greece 2005. European Journal of Dermatology, 16, 662-665.

[10] Camejo, M.I., Mata, G. and Diaz, M. (2003) Prevalence of Hepatitis B, Hepatitis C and Syphilis in Female Sex Workers in Venezuela. Revista de Saude Publica, 37, 339-344. https://doi.org/10.1590/S0034-89102003000300012

[11] Forbi, J.C., Onyemauwa, N., Gyar, S.D., et al. (2008) High Prevalence of Hepatitis b Virus among Female Sex Workers in Nigeria. Revista do Instuto de Medicina Tropical de Sao Paulo, 50, 219-221. https://doi.org/10.1590/S0036-46652008000400006

[12] Marcos, A.M., Divânia Dias, D.S.F. and Megmar Aparecida, D.S.C. (2017) Viral Hepatitis in Female Sex Workers Using the Respondent-Driven Sampling. Revista de Saúde Pública, 51, 1-11. https://doi.org/10.1590/s1518-8787.2017051006540

[13] Husa, P. and Kohoutková, M. (2007) Hepatitis C Virus Infection in Sex Workers. Klinicka Mikrobiologie a Infekoni Lekarstvi, 13, 66-69. https://pubmed.ncbi.nlm.nih.gov/17599295

[14] Laurent, C., Henzel, D., Mulanga-Kabeya, C., et al. (2001) Seroepidemiological Survey of Hepatitis C Virus among Commercial Sex Workers and Pregnant Women in Kinshasa, Democratic Republic of Congo. International Journal of Epidemiology, 30, 872-877. https://doi.org/10.1093/ije/30.4.872

[15] Socias, M.E., Shannon, K., Montaner, J., et al. (2015) Gaps in the Hepatitis C Continuum of Care among Sex Workers in Vancouver, British Columbia: Implications for Voluntary Hepatitis C Virus Testing, Treatment and Care. Canadian Journal of Gastroenterology and Hepatology, 29, 411-416. https://doi.org/10.1155/2015/381870

[16] Zermiani, M., Mengoli, C., Rimondo, C., et al. (2012) Prevalence of Sexually Transmitted Diseases and Hepatitis $C$ in a Survey of Female Sex Workers in the North-East of Italy. The Open AIDS Journal, 6, 60-64. https://doi.org/10.2174/1874613601206010060

[17] Qyra, S., Basho, M. and Bani, R. (2011) Behavioral Risk Factors and Prevalence of HIV and Other STIs among Female Sex Workers in Tirana, Albania. The New Microbiologica, 34, 105-108. 